\title{
TURBINAS Y ELECTRICIDAD PARA LA MINA, LÁMPARAS A PARAFINA PARA LA POBLACIÓN. CRÓNICA DE UNA ASIMETRÍA DEL CAPITALISMO MINERO EN TOCOPILLA (1914-1942)
}

Damir Galaz-Mandakovic ${ }^{1}$

Este artículo describe y analiza la nueva trama local que se produce con la instalación de una poderosa termoeléctrica en Tocopilla en 1914 a través de The Chile Exploration Company. Describimos y analizamos la industrialización satelital de Tocopilla, su rearticulación y redefinición en la dialéctica con Chuquicamata. Proponemos una historización del proceso de termoelectrificación constituyente de una verdadera revolución tecnológica a gran escala. Asimismo, en una segunda parte, describimos el camino y la ilusión comunitaria para lograr la electrificación del pueblo recién en 1942, proceso dado en un contexto de disociación del capital extranjero con el territorio local que constituyó asimetrías.

Palabras claves: Tocopilla - Chuquicamata - The Chile Exploration Company - termoeléctrica - minería cuprífera.

\begin{abstract}
This article describes and analyzes the new local plot that occurred with the installation of a powerful thermal plant in Tocopilla in 1914, The Chile Exploration Company. It is described and analyzed a satellite industrialization of Tocopilla, its re-articulation and redefinition in the dialectic with Chuquicamata. It is proposed a historicization process of thermal electrification, which it is constituent of a true technological revolution on a large scale. Also, in a second part, it is described the means and the community illusion to achieve the electrification system of the people just in 1942, a process occurred in a context of dissociation of foreign capital with the local territory that built asymmetries.
\end{abstract}

Keywords: Tocopilla - Chuquicamata - The Chile Exploration Company - thermoelectric - copper mining.

Recibido: octubre 2015. Aceptado: junio 2016.

\section{* Introducción}

Los hermanos Guggenheim de Estados Unidos forjaron un colosal proyecto para desarrollar industrialmente la mina de Chuquicamata, para lo cual conformaron The Chile Exploration Company el 11 de enero de 1912, en la ciudad de New Jersey, Condado de Hudson (O'Brien 1989).

La ejecución del proyecto minero estableció un importante radio de influencia en distintas comunidades adyacentes, entre ellas el puerto de Tocopilla, distante $140 \mathrm{~km}$ de la mina, comuna en donde se instaló una vanguardista planta termoeléctrica para apoyar todo el proceso extractivo.

De esta forma, se trazó una nueva producción de panorama porque "el capital se esfuerza por producir un paisaje geográfico favorable a su propia reproducción y subsiguiente evolución" (Harvey 2015: 149). Esa configuración fue la expresión de una nueva articulación y dinámica industrial entre el desierto y la costa satelital, dos polos de desarrollo industrial que significaron la instauración de dos territorios con economías de aglomeración (Brueckner 2011). Estos polos, Tocopilla y Chuquicamata, se enlazaron a través de procesos económicos, tecnológicos, mecánicos, logísticos y la configuración de un campo social que atestigua una serie de procesos migratorios,

1 Programa de Doctorado en Historia de la Université Rennes 2 Université Européenne de Bretagne y Programa de Doctorado en Antropología Universidad Católica del Norte. Calle R.P. Gustavo Le Paige 380, San Pedro de Atacama, región de Antofagasta, CHILE.Email: damirgalaz@gmail.com 
laborales, urbanos e identitarios, derivados, en gran medida, de la presencia del consorcio norteamericano. ${ }^{2}$

En la inauguración de este proceso minero, Tocopilla transitó desde una exterioridad complementaria, registrada en un momento preindustrial de Chuquicamata, hacia una inclusión funcional una vez que el escenario de industrialización fue instalado.

Al mencionar esa exterioridad complementaria con Chuquicamata, indicamos que el puerto estaba implicado en la dinámica minera de Atacama desde la década de 1840, o sea mucho antes de The Chile Exploration Company. Pero esa dinámica y vinculación con Chuquicamata era de una relevancia menor. Sus relaciones y sus desarrollos eran autónomos y escasamente articulados; era la exportación de salitre del cantón El Toco lo que dinamizaba la economía tocopillana.

Entonces, esa exterioridad complementaria que representaba Tocopilla para la heterogénea minería en Chuquicamata estaba dada por la presencia de muelles, el envío de productos marinos, prestación de mano de obra $\mathrm{y}$ tenues migraciones al mineral chuquicamatino.

Al momento de incluir funcionalmente a Tocopilla, en 1914, se constituyó un nuevo proceso que significó un enlace directo con la Chuquicamata de The Chile Exploration Company, una participación y articulación moderna, capitalista y satelital. Tocopilla pasaba a ser parte de un triángulo geográfico utilitario para el proyecto cuprífero constituido por Chuquicamata, la mina; Tocopilla, la termoeléctrica y Antofagasta, el puerto.

La implementación de la termoeléctrica incluyó un rol logístico y productivo que adicionó un nuevo proceso de proletarización, transformaciones urbanas, una nueva influencia extranjera de sus dinámicas sociales y una polución estructural.

\footnotetext{
2 Gunder Frank (1978) indica que los polos tecnológicos están basados, usualmente, en firmas grandes y bien capitalizadas, que históricamente han sido rastreadas y localizadas en Estados Unidos o Europa occidental, las cuales invierten en la producción de un bien de exportación destinado a los mercados de origen de la empresa inversora.
}

Este tipo de infraestructura en la costa tocopillana, estuvo completamente delimitada y condicionada al uso exclusivo de actividades productivas que en el decir de Pietrobelli y Rabelotti (2005), fueron generando severas fronteras dentro de la misma ciudad, abarcando divorcios desde la arquitectura hasta la tecnología. No obstante, gran parte de los trabajos que hablan sobre la épica chuquicamatina invisibilizan los procesos vividos en sus márgenes, centrándose solo en la mina, como un fenómeno insular, sin considerar los poblados que vertieron sus dinámicas para participar en este proceso de industrialización minera.

De este modo, la zona de Tocopilla fue constituida como una "zona invisible" en la historiografía y antropología regional. Esta invisibilización se sitúa entre el conjunto de trabajos que se ha ocupado de estudiar la gran transformación de Atacama por la inauguración industrial de Chuquicamata y los trabajos contemporáneos que abordan problemáticas centradas en contaminación, manejo de aguas y problemáticas con algunas comunidades indígenas, invisibilizando los fenómenos densos ocurridos en la costa tocopillana, al menos en la primera mitad del siglo XX. ${ }^{3}$

Esta invisibilización no solo se da en las ciencias sociales, sino que también a nivel cinematográfico y corporativo: en el año 1950 The Chile Exploration Company produce su gran filme Cobre, vida y milagros de un metal, dirigido por Pablo Petrowitsch, famosa película corporativa que dio la vuelta al mundo y que al momento de hablar del "lugar en donde se produce la electricidad", no menciona a Tocopilla, simplemente habla de la "costa", en donde "se encuentra una gran fábrica de electricidad...". Después de esa frase, vienen imágenes del mar, perfiles de las torres de alta tensión y un silencio del narrador.

Ante esos silencios y borraduras, nos preguntamos: ¿Cómo fue la experiencia tecnológica, técnica y social

\footnotetext{
3 Por ej.: Macchiavello 1923; Latcham 1926; Gutiérrez 1926; Figueroa 1928; Arce 1930; O’Connor 1937; Martínez 1943; Bermúdez 1963; Zapata 1975, 1977, 1979; French-David y Tironi 1974; Alvear 1975; David 1978; Fox-Przeworski 1980; Rossi 1997; Collao 2001; Tapia 2001; Recabarren 2002; Aroca 2002; Valenzuela 2004, 2005; Sanhueza 2007; Garcés, Cooper y Baros 2007; Gutiérrez-Viñuales 2008; Campdelacreu 2009; COCHILCO 2009; Gómez 2010; Ardiles 2010.
} 
de esta inserción tecnológica e industrial una vez que The Chile Exploration Company industrializa la mina de Chuquicamata, incluyendo funcionalmente Tocopilla a través de la instalación de una gran termoeléctrica en 1914? Asimismo, ide qué modo este proceso industrial convivió o se desarticuló del resto del territorio produciendo una agresiva frontera técnica, transnacional, cerada y simbólicamente violenta?

Este artículo describe y analiza la nueva trama local que produce la industrialización satelital de Tocopilla, su rearticulación y redefinición en la dialéctica con Chuquicamata a contar de 1914. Proponiendo una historización del proceso de termoelectrificación en manos de The Chile Exploration Company, una verdadera revolución tecnológica a gran escala. Asimismo, en una segunda parte, caracterizaremos la microhistoria subalterna del camino y la ilusión comunitaria para lograr la electrificación del pueblo en un marco de violenta e irónica disociación o desvinculación de este proceso industrial con el territorio local, produciendo un territorio bifurcado con una escala asimétrica.

Metodológicamente este trabajo se apoya en la información obtenida en archivos situados en cuatro niveles: capital, Estado, prensa y sujetos. Es decir, archivos de la empresa y sus instancias intermedias; archivos administrativos estatales de la Municipalidad, Gobernación de Tocopilla e Intendencia de Antofagasta; archivos periodísticos, diarios La Opinión y La Prensa de Tocopilla y memorias de sujetos.

\section{* Termoelectrificación desde la costa}

The Chile Exploration Company se instala en Tocopilla después de que el gobierno de Ramón Barros Luco impugnara la concesión en el antiguo puerto de Cobija. ${ }^{4}$ Este rechazo fue por el lobby de los políticos locales y provinciales y se sustentó en la campaña comunitaria que contrariaba la concesión. ${ }^{5}$ En tales circunstancias, se

4 Ex puerto boliviano (1825-1879). Distante $60 \mathrm{~km}$ al sur de Tocopilla.

5 Las noticias del proyecto de una planta generadora de energía se documentan en el año 1913. El lugar elegido era el devastado puerto de Cobija. Sin embargo, los vecinos tocopillanos reclamaron fuertemente a las autoridades para que no se autorizara la concesión a esta compañía en el citado puerto, ya que traería, eligió Tocopilla por su cercanía con Chuquicamata, pero sobre todo por la obtención de agua de mar. Tocopilla ni siquiera fue proyectado como puerto para el cobre de Chuquicamata a saber de la existencia de un ferrocarril (FCTT). Entonces, se consideró Antofagasta, articulado por otro ferrocarril (FCAB) como el puerto para exteriorizar la producción cuprífera. ${ }^{6}$

Hecha la impugnación de la concesión de la Coast Plant en el puerto de Cobija, la compañía adquirió terrenos en el sector conocido como Península de Algodonales, protegiendo con pertenencias mineras las propiedades que fueron adquiridas a la salitrera H. B. Sloman y Cía. en marzo de 1914 (AGT, Plano de bahía Algodonales presentado por The Chile Exploration Company, 12 de febrero 1914).

El 28 de marzo de 1914, la Intendencia de Antofagasta, a través del subsecretario del Ministerio del Interior, informó del nuevo Decreto Supremo que autorizaba la instalación de la planta en Tocopilla:

Apruébese el proyecto presentado por el señor James Walmsley, por los señores Duncan Fox y Compañia, representantes de The Chile Exploration Company para instalar planta eléctrica en

supuestamente, un menoscabo económico a Tocopilla: se acrecentaría la emigración fuertemente iniciada durante la fiebre amarilla de 1912 (Galaz-Mandakovic 2009) y se disiparía la importancia en el concierto provincial. Otro argumento evidenciaba el nacionalismo local: se apuntaba a que Cobija, aniquilado por el maremoto de 1877 , se convertiría en un verdadero "feudo gringo", situación que revertía el proyecto nacional diseñado para las recientes incorporaciones territoriales, que solo llevaban 35 años. Estas protestas las hallamos en variadas ediciones de los diarios La Correspondencia, El Liberal, El Trabajo y El Deber, todos de Tocopilla. No obstante, el proyecto de un ferrocarril entre Chuquicamata y Cobija, era lo que más asustaba a la Agrupación de Vecinos Pro-Tocopilla, formada por comerciantes, periodistas, políticos y vecinos (Diario La Correspondencia, 13 de abril 1913). Entre los férreos oponentes estuvo el diputado Lindorfo Alarcón y el médico Víctor Alzérreca, quienes realizaron gestiones al más alto nivel, junto al alcalde de Tocopilla, Próspero Borjes, para evitar el emplazamiento de la compañía en el otrora puerto boliviano.

6 El proyecto norteamericano tuvo que superar una larga lista de dificultades. Entre ellas, asumir la implementación de una termoeléctrica en una península en una región con reciente historial sísmico: estaba fresca la memoria de dos potentes catástrofes: los terremotos y maremotos de 1868 y 1877 . 
Tocopilla, para transmitir energía de alta tensión a Chuquicamata, con conformidad al plano y memoria explicativa que quedan archivados en la oficina técnica de acuerdo a la Ley $N^{\circ} 1665$ del 4 de agosto de 1904 sobre permiso de instalaciones eléctricas. [...] $3^{\circ}$ : los trabajos deberán iniciarse en el plazo de seis meses [...] autorizase al Gobernador de Tocopilla para que en representación del Fisco firme la escritura pública a que deberá reducirse el presente decreto. R. Barros Luco, Rafael Orrego, Julio Fabres (AGT, Decreto 457, 28 de marzo 1914. Intendencia de Antofagasta, a través del Sub Secretario del Ministerio del Interior).

Según la reseña de Siemens Schuckert Werke llamada Die Anlagen der Chile Exploration Company in Tocopilla und Chuquicamata (1920), se indicaba que uno de los principales escollos para el proyecto lo representaba el clima del desierto y la escasez de agua. Señalando que, "para el agua de refrigeración se tuvo que obtener en Tocopilla por destilación de agua de mar" (1920: 136). Este mismo informe comenta lo dificultoso del contexto internacional, puesto que toda la construcción se llevó a cabo durante la Primera Guerra Mundial. Era extremadamente difícil el transporte de las maquinarias provenientes de Hamburgo y Bremen (SSW 1920).

Finalmente, a través del hilo telegráfico, el presidente Ramón Barros Luco, desde el Palacio de La Moneda, inauguró el 18 de mayo de 1915 la termoeléctrica en Tocopilla dando paso al proceso de extracción y electrolisis en Chuquicamata (ElMercurio, 19 de mayo 1915).

\section{Inserción tecnológica}

Al momento de su inauguración en mayo de 1915, la usina contaba con cuatro unidades que significaron el montaje de 16 calderas de 600 caballos de fuerza y cuatro turbinas que producían 40 mil kilovatios. Las instalaciones fueron construidas por la Casa Siemens Schuckert de Alemania (Illanes 1915). Las calderas Babcock estaban provistas de tubos para agua para producir vapor saturado a 215 libras, el cual al ser sobrecalentado obtenía una temperatura de $525^{\circ} \mathrm{F}$ (SSW 1920).

Siguiendo a Guillermo Illanes que, en su calidad de director general de Obras Públicas de Chile, realizó una visita en mayo de 1915 al mineral de Chuquicamata, ${ }^{7} \mathrm{pa}-$ sando también por Tocopilla, nos cuenta:

En Tocopilla hay instaladas dieciséis calderas del tipo Babcock y Wilcox, de 2,500 kW. Estas calderas están provistas de supercalentadores y economizadores, y trabajan a una presión de 12,68 kilogramos por centímetro cuadrado. Al vapor se le da un supercalentamiento y su temperatura final deja a las calderas con 287.5 grados centígrados (Illanes 1915: 25-26).

Sobre el detalle de las calderas, nos indica: "son de combustión a petróleo [...] El agua para alimentación de las calderas se deriva de una instalación evaporadora de agua salada. El vapor de la calderas mueve cuatro turbinas hechas por la Escher Wyss \& Cía. de Zurich, Suiza" (Illanes 1915: 26).

Debemos consignar que cada turbina estaba acoplada a un generador de $10.000 \mathrm{~kW}$.

Estos generadores producen una corriente alternativa trifásica de 50 ciclos a 5,000 voltios y 2,000 amperios, que después de pasar a través de los tableros del registro y aparatos de seguridad, se cambia en cuatro transformadores de aumento Siemens Schuckert de $10.000 \mathrm{~kW}$ a una tensión de 110.000 voltios (Illanes 1915: 26).

Todo este proceso no hubiese sido posible sin la construcción de un túnel para extraer agua de mar. El 21 de julio de 1914, se decretó la concesión del terreno,

...por un término de cinco años y por la renta anticipada de un peso (\$1) por metro cuadrado, a The Chile Exploration Company, con el objeto de construir un túnel que facilite la conducción de agua de mar para desarrollar energía eléctrica y dar movimiento a las maquinarias de dicha compañía. Barros Luco. Ricardo Salas (AGT, Oficio 1990, al Sr. Gobernador. Santiago).

La implementación exigió la instalación de grandes estanques para depositar el petróleo importado por The Union Oil Company of California. ${ }^{8}$ Para ello, el mismísi-

7 Este itinerario fue para elaborar un informe al gobierno de Ramón Barros Luco, por ello contó con la colaboración del gerente general Federico Hellmann como también con la colaboración del ingeniero químico y metalurgista Elias Anton Cappelen Smith. En Tocopilla se contó con el guiado del ingeniero Pope Yeatman. 8 Fue fundada en 1890 con el nombre de The Union Oil Company 
mo presidente Ramón Barros Luco decretó el 12 de junio de 1914 la concesión de terrenos:

Concédase en arrendamiento a The Union Oil Company OfCalifornia por el término de cinco años y por la renta anual anticipada de dos y medio centavos (\$0.025) por metro cuadrado con el objeto de instalar estanques para depósito de petróleo de dos hectáreas de terrenos fiscales situadas al sur del puerto de Tocopilla. The Union Oil Company of California pagará quinientos pesos (\$500) oro. Barros Luco, Ricardo Salas. (AGT, Santiago, 12 de junio 1914, Decreto Supremo 382).

Estos estanques estaban especialmente remachados para el almacenamiento de petróleo traído directamente desde California: "cada estanque tiene la capacidad de 55.000 barriles cada uno" (Illanes 1915: 26). Se usarían alrededor de mil barriles diarios9 (Martínez 1943).

En el sector en donde se emplazaron los estanques, en la punta de la bahía Algodonales, se había levantado un improvisado barrio habitado por portuarios e inmigrantes de la zona central de Chile. Este barrio era conocido como la "Población de Lata", predominando tolderías de oxidadas calaminas, latas extendidas de tambores, maderas y sacos salitreros. La termoeléctrica y los estanques enormes provocaron una erradicación y borradura con este barrio y también con populares balnearios y hoteles, entre ellos, Los Baños del Zavala. Igualmente, estos depósitos constituyeron toda una novedad en la comunidad, un impacto visual - no se conocían estanques tan grandes como aquéllos-y también curiosidad; ;0 surgió el

de California pero al poco tiempo comenzó a ser conocida como Unocal (Welty et al., 1966).

9 La descarga de petróleo era realizada a través de cañerías flotantes y submarinas. Fue así que, en junio de 1914, Harvey Diamond, representando a The Chilex Exploration, pidió la autorización para instalar una cañería flotante movible "cada vez que sea necesario para descargar un vapor" (AGT, Oficio 192, adjunta Decreto del Min. de Hacienda 1694 del 12 de junio 1914).

10 Incluso, con el pasar de los años, estos estanques siguieron constituyendo una novedad material para los tocopillanos, llegando al punto de existir verdaderas romerías que acudían al sector para observarlos. Esto lo dejó en claro una carta enviada a la Gobernación por parte del guardia de los estanques, quien solicitaba armas "contra los mirones". El documento consignó: "Sr Gobernador Juan Bautista Fuenzalida: como ha pasado jente penetrando el establecimiento con intención de mirar y molestar [...] quien suscribe pide permiso por Cleofa Vega y José Bonilla cuidadores temor de los vecinos: el miedo a un derrame o a un gran incendio inquietaba a los tocopillanos (Diario El Proletario, 13 de septiembre 1914).

\section{El célebre cronista Marcial Figueroa comentó:}

...no olvidaremos decir que en esos estanques donde hay diariamente un gran almacenamiento de petróleo [...] más de una vez hemos oído decir a varios tocopillanos que la ubicación de esos estanques está muy cercana a la población, máxime que están en un costado inaceptable de ella, encerrando un gravisimo peligro, por lo que deben ser trasladados al barrio opuesto, como un deber de humanitarismo (Figueroa 1928: 191).

El traslado sugerido por Figueroa en 1928, quien decía transmitir el vox populi, nunca fue realizado.

Desde todas estas instalaciones para generar la termoelectricidad, se inició un sistema de postación que atravesó toda la cordillera de la Costa, luego la depresión intermedia hasta llegar a Chuquicamata, situada a 140 $\mathrm{km}$ y a una altura de $2.760 \mathrm{msnm} .{ }^{11}$ Torres de alta tensión, separadas en promedio por 200 metros, que inscribieron una estética capitalista en el desierto. ${ }^{12}$ La línea

de los estanques de petróleo que la Union Oil Company of California posee al sur de esta ciudad. Ramsay Hunter Shankie a Ud. digo que teniendo que resguardar los cuantiosos intereses de mis patrones en el sitio de los estanques que están lejos de la población y sujetos a esta clase de peligros, me veo en la necesidad de esta solicitud. Por consiguiente se sirva conceder permiso para cargar revólver durante las horas de servicio. (AGT, carta de Union Oil Company of California. Ramsay Hunter Shankie. 20 de febrero 1919).

11 En el recorrido de las líneas eléctricas de Tocopilla hasta Chuquicamata, se encontraban los terrenos salitreros reputados de baja ley y que pertenecían a las firmas Lautaro Nitrate y Anglo Chilean Consolidate Nitrate Company. La firma Guggenheim Bros. compró la mayor parte de las acciones de Lautaro Nitrate y en seguida hizo otro tanto con las acciones de la segunda compañía (Ortiz 2005).

12 Eulogio Gutiérrez describió: "Vistas estas torres en plena pampa del Toco, semejan de lejos los baluartes escalonados de una línea de batalla. Es una hilera interminable cuya línea se pierde en la lejanía del horizonte" (Gutiérrez 1926: 84). Por su parte, el escritor Marcial Figueroa dijo: "Con el espejismo de la pampa, esas torres vistas desde lejos asemejan atalayas que resguardan la vida de los que vivaquean dentro de un campo de operaciones" (1928: 183). 
1 constaba de 717 torres, la línea 2 de 598 y la tercera línea, también contaba con 598. En total, desde el puerto de Tocopilla partían 1.913 torres de alta tensión (Illanes 1915). Cada una con ocho aisladores con una resistencia de 85.000 voltios.

Después de los $140 \mathrm{~km}$ de transmisión eléctrica, la energía era entregada a la subestación eléctrica "A" en Chuquicamata, "pasando por varios artificios protectores llega a los transformadores $10.000 \mathrm{~kW}$, de los cuales hay cuatro para bajar la tensión a 5000 voltios. De aquí pasa a los colectores de 5000 voltios para su distribución" (Illanes 1915:31).

Una vez allí, cerca de $18.000 \mathrm{~kW}$ pasaban a siete convertidores giratorios, cuatro del tipo de inducción y tres del tipo sincrónico. A la subestación "B" pasaban 3.000 $\mathrm{kW}$, en donde había tres transformadores de $1.000 \mathrm{~kW}$ que reducían la corriente a 525 voltios. Éste era el voltaje operativo de todos los motores en el establecimiento, con excepción de los que movían los generadores de corriente directa (Illanes 1915: 31). Entonces, los conductores, desde los tres transformadores de $1.000 \mathrm{~kW}$, entregaban a los colectores de 525 voltios en el área subterránea de la estación en donde se realizaba la distribución a los motores de la instalación. Por su parte, otra porción, alrededor de $3.000 \mathrm{~kW}$ se elevaba directamente de los colectores de 5.000 voltios a la subestación "C" que estaba situada al oriente de la instalación.

En el decir del funcionario Illanes,

...dicha porción se transformaba pasando por tres transformadores de $10.000 \mathrm{~kW}$. Cada uno, en una tensión de 525 voltios, de aqui pasa a los colectores y en seguida se reparte a los motores, situados inmediatamente. Una parte de la fuerza se ha dispuesto también para la mina en donde se usará para el alumbrado, malacates a electricidad para mover las compresoras de aire, etc. (Illanes 1915: 32).

El cronista de Obras Públicas apostillaba:

Refiriéndonos a la producción de cobre, la casa de estanques electroliticos existente, se estima que tiene una producción total de 152.272 kilogramos por día. En otras palabras, la instalación existente, trabajando a su capacidad completa, producirá 150 toneladas de cobre al día, 4.256 por mes de 28 días de trabajo, y por año alcanzaría a 51.072 toneladas. La instalación en proyecto producirá tres veces más, es decir, 456 toneladas diarias, 12.768 toneladas mensuales, y 153.216 toneladas al año (Illanes 1915: 33).

El aumento de la producción en Chuquicamata, repercutió en Tocopilla a través de las ampliaciones de la planta. Por tal razón se evidencian seguidas peticiones ante las autoridades para expandir las instalaciones en varias hectáreas y de este modo poder satisfacer la demanda eléctrica de la mina, en especial para el proceso de electrolisis. ${ }^{13}$

Las primeras instalaciones contaban con un grupo generador de $10.500 \mathrm{~kW}$ marca AEG que utilizaba vapor de 750 libras, tres generadores de $10.000 \mathrm{~kW}$ marca Escher Wysc Co., que empleaban vapor a 220 libras de presión. Además, un turbogenerador de $20.000 \mathrm{~kW}$ General Electric que también usaba vapor de 220 libras; dos turbogeneradores de $20.000 \mathrm{~kW}$ General Electric y un turbogenerador de igual marca de solo $3.000 \mathrm{~kW}$ que se utilizaba para los equipos auxiliares, con 220 libras de vapor. Cada uno de los turbogeneradores, con excepción del primero, tenía un condensador tubular de superficie, el cual era refrigerado por agua de mar.

$\mathrm{Al}$ año siguiente de la puesta en marcha de la planta termoeléctrica, la compañía instaló otras tres unidades, significando también la construcción de 12 nuevas calderas. La planta se constituyó en una de las más modernas del mundo y de las primeras en transmitir energía a tan alta tensión (Gutiérrez 1926). En esa misma fecha poseía una potencia mayor que la de las empresas que en el futuro formarían Chilectra, las que abastecían Santiago y Valparaíso (Martínez 1943).

La importancia de Tocopilla, en cuanto productor eléctrico, era vital para la mina y esto se notaba en la administración del consorcio en Chile, probablemente por esa razón y poder de la electricidad, Burr Wheeler, que era de profesión ingeniero eléctrico, llegó a ser el tercer gerente general de The Chile Exploration en Chile, después de Hellman y Bellinger (Parsons 1933).

13 La empresa propietaria resolvió introducir por primera vez en Chile el proceso de lixiviación por electrolisis, resultando una importante innovación que superaba los sistemas de concentración y fundición tradicionales. 
En los inicios del año 1917, la compañía norteamericana solicitó el arriendo de terrenos para aplicar otro plan de ensanche. A fines de septiembre se iniciaban los montajes de grúas que servirían para efectuar las ampliaciones de la planta. En nota dirigida al intendente, se imploraba el arrendamiento en conformidad a lo dispuesto en el Código Civil (Art. 602), lo que significó usarlos mientras la usina permaneciera en funciones en la ciudad de Tocopilla. Esto confería cierto grado de infinitud de la posesión de los terrenos.

En una de las diversas correspondencias halladas en los archivos de la Gobernación de Tocopilla, Wagner, en representación de la empresa, indicaba en la solicitud de terrenos: "nada valen para el Fisco y nunca podrán tener aplicación más útil y provechosa para los intereses generales". De este modo ejercía cierto grado de presión y despotismo al insinuar que ningún emprendimiento superaría las inversiones estadounidenses. En esta misiva, Wagner corona directamente la solicitud:

En cuanto al término de la concesión, debe en mi concepto concederse tal como lo solicita el interesado, por el tiempo que duren las necesidades de mantener en pie la planta eléctrica generadora de energía, que va al mineral de Chuquicamata. Concederla por diez años por ejemplo, es para estar repitiendo periódicamente esta misma tramitación, desde que se sabe que hay minerales que explotar para más de cincuenta años, por lo menos y, sobre todo cuando una vez otorgada la concesión, no podrían seguir negándose las prórrogas venideras sin provocar la ruina de un negocio que deja positivos beneficios para el país (AGT, carta $\mathrm{s} / \mathrm{n}$ al Gobernador e Intendente, 15 de abril 1917).

Como resultado de las ampliaciones logradas, lo que incluyó una expansión territorial en la Península de Algodonales (Figura 1), la planta termoeléctrica contaba en 1918 con significativas instalaciones que marcaban una gran diferencia con la inicial planta de 1915.

En ese escenario, el ensanche del cuerpo central de los edificios fue sustancial para instalar las nuevas calderas que poseían un mayor caballaje, esta vez de 1.350 H.P. Se agregó al mismo tiempo un turbogenerador de $10.000 \mathrm{~kW}$ con sus correspondientes accesorios, incluyendo un transformador de gran potencia (Figura 2). Además de esta ampliación, fue instalado un vaporizador con capacidad para destilar 10 toneladas de agua por hora (Collao, 2001).

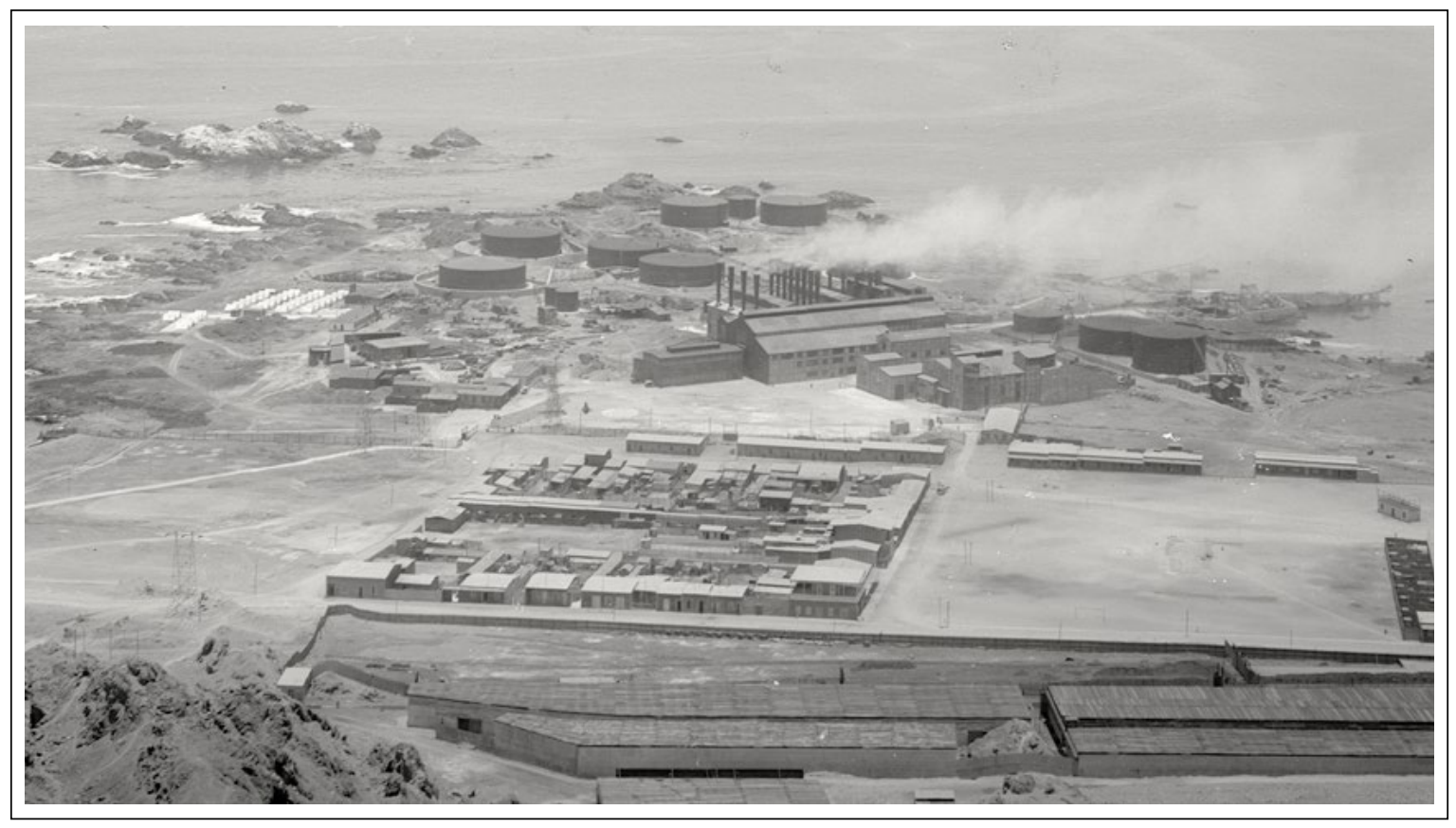

Figura 1. Instalaciones de la termoeléctrica de The Chile Exploration Company en la Península Algodonales de Tocopilla, 1925. Archivo (C) Damir Galaz-Mandakovic. 


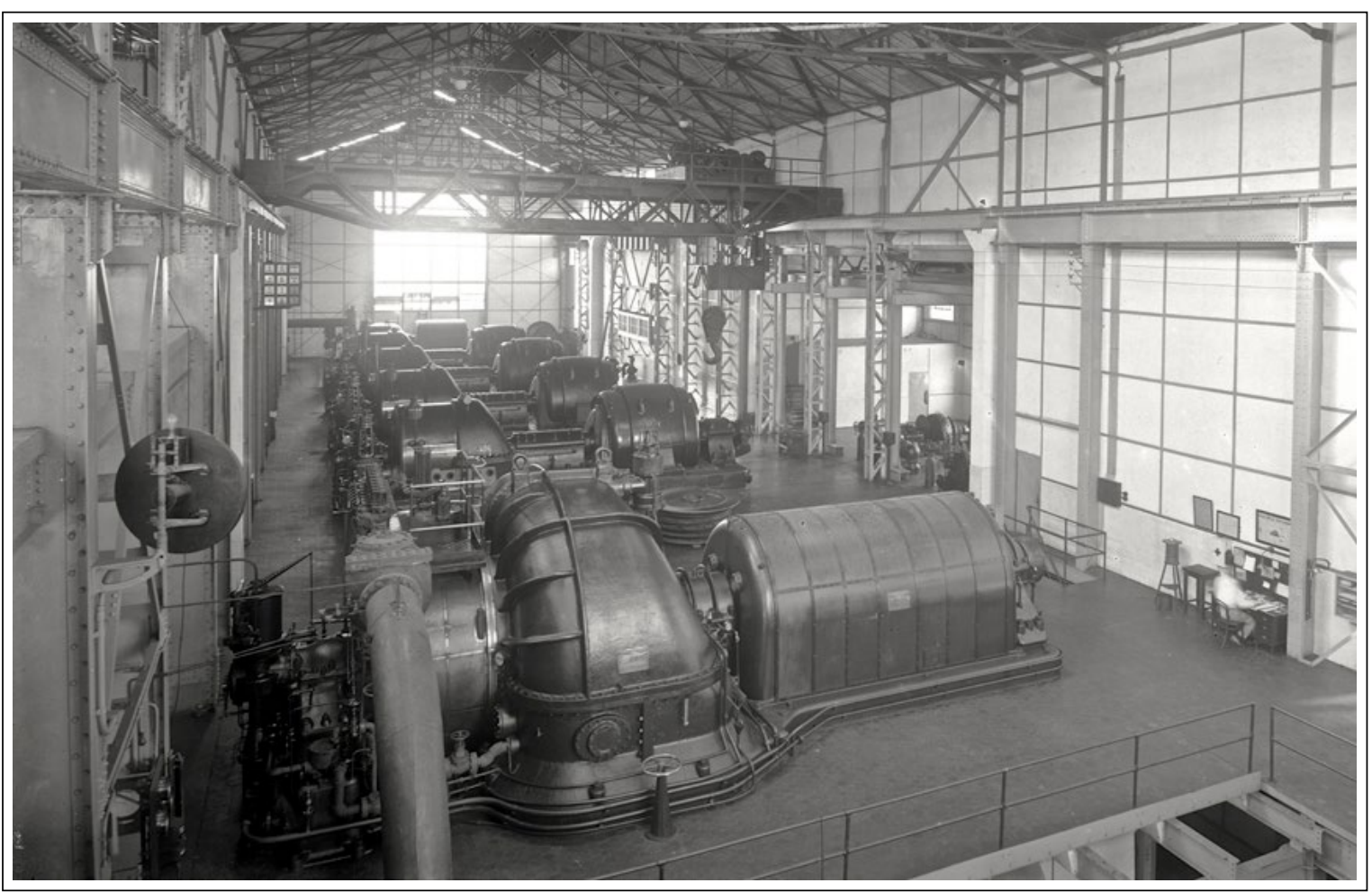

Figura 2. Sala de turbinas. Las instalaciones fueron construidas por la Casa Siemens Schuckert de Alemania, 1915. Archivo (C) Holly Peterson, New Jersey.

Todo esto significó un movimiento de tal envergadura que la compañía debió recurrir a una nueva masa laboral, significando la llegada en abril de 1918 de un "enganche" de obreros en el famoso vapor Maipo: "Por esos mismos días, otros enganchadores especiales recorrían Iquique y Antofagasta buscando mano de obra para la Chile Exploration. Pero, los del enganche eran procedentes del sur, principalmente carpinteros, albañiles y mecánicos" (El Proletario, 3 de abril 1918).

El despliegue territorial de la compañía fue constantemente ampliándose en la península de Algodonales; cada decisión y proceso en Chuquicamata, repercutía en Tocopilla. ${ }^{14}$

14 Las propiedades de la compañía estaban tasadas de común acuerdo con la Municipalidad de Tocopilla en 1919, llegando a la cifra de 11 millones. No obstante, el aumento era evidente y sustancial, lo que significó la necesidad de efectuar nuevas tasaciones. En 1923 la extensión sur de la planta quedaba avaluada en \$1.415.055.50 según la empresa. El Municipio aceptó ese valor respaldado por la opinión de Rafael Godoy, ingeniero del Servicio de Impuestos Internos de Antofagasta (Collao 2001:326).
Según el diario El Mercurio de Santiago, en una edición especial sobre historia de Chile, indica:

A la crisis económica que se produce en Chile al comienzo de la Primera Guerra Mundial siguieron años de prosperidad, efecto de la creciente demanda de cobre y de salitre por los beligerantes. En efecto, la incorporación de capitales y refinadas técnicas a la extracción de cobre, con la incorporación de Chuquicamata a la gran minería en 1915 el promedio de producción de cobre bordeaba las 10.000 toneladas. Luego se alcanzó la cifra de 100.000 durante los años 1917-1918 (El Mercurio de Santiago, 1 de junio 1975).

Evidentemente, durante la Primera Guerra Mundial se inició un gran aumento en las exportaciones de cobre. En 1920 el valor exportado fue de 283 millones de pesos de 6 peniques (Collao 2001).

El segundo cuerpo de la planta de baja presión fue instalado en 1926, es decir, 11 años después de la primera sección. En esos años montaron seis calderas que pro- 
ducían vapor saturado a 200-215 libras sobrecalentando a 550 F. Esas calderas fueron diseñadas para una potencia de 1.403 E.P.B. Tenían tubos inclinados y trabajaban calentadores de vapor y economizadores. El número de quemadores por cada caldera alcanzaba a 11, produciendo una presión en colector horizontal de 225 libras por pulgada cuadrada. La evolución de sus instalaciones, producto del crecimiento del yacimiento cuprífero, la llevó a consolidar la denominada Planta de Baja Presión (unidades 1 a la 7) y la Topping Plant (Unidad 8) en 1938 hasta alcanzar una potencia de $80.00 \mathrm{~kW}$ (Martínez 1943).

\section{* Tecnologización disociada}

Cuando hablamos de esta inserción tecnológica, atestiguamos el surgimiento de una nueva cartografía que desde lo regional se conecta a un importante escenario del capitalismo mundial, emergiendo una supremacía de un consorcio extranjero transformador de la costa de Atacama.

La compañía estadounidense ejecutó una verdadera revolución tecnológica, mecánica, modificaciones viales y nuevos flujos, una impronta material, urbana y un fuerte impacto ambiental por la quema de combustibles fósiles en un espacio delimitado y con un fuerte impacto social en el poblado tocopillano, el cual vertió sus dinámicas locales a los requerimientos funcionales de la compañía estadounidense. ${ }^{15}$ Para Schumpeter (1942), en el capitalismo moderno la innovación ya no es una aventura sino una actividad organizada y costosa.

No obstante, vemos que este proyecto y proceso industrial, no funcionó como una "economía con apuesta dinámica o integradora" tanto a nivel local como nacional (Levin, 1960; Cademartori, 2010). Es decir, surgió un enclave ${ }^{16}$ tecnológico que también fue la expresión de una

15 Una vez implementada la termoeléctrica, el consorcio estadounidense dio paso a la construcción de un company town o village workers desde el primer lustro de la década de 1920. Estos campamentos para obreros y empleados fueron denominados como Las Villas, entre ellas Villa Covadonga y Villa Americana. Tocopilla se dividió en dos grandes segmentos: entre "la villa" y "el pueblo", una nueva forma de relación en el territorio marcado por la segregación y relaciones de alteridad socioeconómica y laboral. 16 En geografía política un enclave remite a una zona aislada por un territorio que le es ajeno. Por ejemplo: El Vaticano situado den- disociación con el territorio: la planta eléctrica de Tocopilla desde 1915 superaba la potencia de Potomac Electric Power que abastecía a Washington; esta potencia de vanguardia duró hasta la década de 1950, "de la energía entregada en Tocopilla, entre un $75 \%$ y un $85 \%$ eran destinada al proceso electrolítico" (Martínez 1943: 44).

Sin embargo, Tocopilla, el "puerto de la luz" para toda la épica cuprífera, era una ciudad que se encontraba a oscuras. La termoeléctrica invisibilizó a la ciudad y le negó la electricidad. Como veremos, la energía eléctrica llegó recién al poblado en abril de 1942. Es decir, los tocopillanos recién pudieron disponer de electricidad 28 años después de la llegada de la termoeléctrica de vanguardia.

Según Sotelo Valencia (2004) entre los elementos que define a un enclave está la disociación con el comportamiento del sector productivo interno del país. O bien, como afirmó Harvey, "sin el desarrollo geográfico desigual y sus contradicciones, el capital se habría osificado hace tiempo y habría caído en el caos. Es un medio clave para la reinvención periódica del capital por sí mismo" (2015: 149).

Una planta eléctrica destacada mundialmente estaba emplazada en una sombría ciudad. Usinas eléctricas de delantera continental convivían con lámparas a parafina y con velas de la población local. Una violenta frontera y paradoja marcada por la técnica. Una relación asimétrica entre los grupos locales y los foráneos que solamente vincularon a Tocopilla con el mercado mundial, implicando una dualidad entre el propio enclave como sector capitalista tecnológicamente avanzado, y su periferia, un sector tradicional y completamente lóbrego. Resultaba inconcebible para los ciudadanos contar con una modernísima termoeléctrica dentro del radio urbano, mientras

tro del territorio italiano, Guantánamo como reserva de Estados Unidos en Cuba, Lesoto en Sudáfrica, etcétera. En el contexto de nuestro trabajo, el concepto se inscribe desde la teoría del enclave económico que constituye a la vez un enclave tecnológico, es decir, un pequeño territorio cerrado que compone una importante diferencia y alteridad con Tocopilla. El enclave puede ser caracterizado como territorio en los que se habilitan condiciones económicas especiales en relación al resto del Estado-nación en que se ubican para el desarrollo de actividades económicas de diverso tipo por parte de transnacionales en forma directa o indirecta (Falero 2015). 
al mismo tiempo, no se contaba con electricidad en sus hogares y la ciudad estaba a oscuras. La situación de la pequeña Empresa Eléctrica Mandakovic \& Vlastelica era crítica, porque la demanda comenzó a aumentar y, a mayor demanda, mayor fragilidad y precariedad de los generadores de estos empresarios yugoslavos que trabajaban desde 1912 con apenas dos motores y solamente cubrían algunas cuadras de la población.

En esas circunstancias, sobrevienen innumerables gestiones, solicitudes, reclamaciones que constituirían un proceso comunitario peticionista y mendicante hacia una reticente compañía norteamericana.

\section{El camino de las peticiones}

Después de nueve años de funcionamiento de la usina eléctrica estadounidense, las autoridades tocopillanas comenzaron a formalizar las peticiones. La Municipalidad en sesión del 12 de mayo de 1924 acordó pedir al gobernador un trabajo en conjunto para solucionar la demanda de electricidad por parte de la ciudadanía.

La Municipalidad acordó pedir a Ud. su valioso concurso a fin de que asesore a una comisión que se ha nombrado, compuesta del Primer Alcalde, Carlos Bañados y Leopoldo Barrientos para que se apersonen al señor Jerente de la Chile Exploration hoy a las 4 de la tarde, para ver si se puede conseguir que esta compañia diera luz eléctrica a la población. Carlos Bañados (AGT, carta $\mathrm{n}^{\circ} 34$ al Gobernador de Tocopilla, 27 de mayo 1924).

El tiempo siguió marchando sin mostrar novedades respecto a las peticiones a The Chile Exploration Company. En esas circunstancias de negación, la Municipalidad discutió en innumerables ocasiones la posibilidad de implementar una planta eléctrica propia y poder superar la oscuridad, tal como lo hemos visto en la numerosa documentación del archivo consistorial.

Ante las insistencias, en marzo de 1928, el gobernador de Tocopilla recibió una respuesta del gerente general del consorcio termoeléctrico y minero Alfred Houston (residente en Santiago de Chile), quien respondía a una serie de preguntas y mociones.

Sr. Florencio Tornero, Gobernador. Estimado: he tenido el agrado de recibir su atenta fecha del 9 del presente, relativa a si seria posible que The Chile Exploration proporcionara en alguna forma energía eléctrica para el alumbrado público de la ciudad de Tocopilla, asunto que me alegro que usted haya tocado en esta ocasión por cuanto he podido discutirlo con los señores H.C. Bellinger y Burr Wheeler, aprovechando la presencia de ellos en Santiago. Puedo adelantarte que este asunto lo hemos considerado con toda atención requerida, y que especialmente yo he procedido de esa manera por la personal consideración que debo a usted. Sin embargo, la cuestión propuesta ha sido en realidad suscitada ante nosotros cada vez que un nuevo funcionario ha ocupado esa Gobernación, pero ellos han comprendido la necesidad de atender a los servicios públicos de Tocopilla y no han encontrado para eso otro modo de solicitar la cooperación de una compañía particular (AGT, carta s/n Alfred Houston, Santiago, 21 de marzo de 1928).

En el decir del escribiente, se concibe que cada uno de los gobernadores que asumían en Tocopilla, realizaba la petición. No obstante, las respuestas adquirieron una condición técnica:

Fundamentalmente, debo ante todo declararle que la planta para la energía eléctrica de esta compañía fue calculada y construida con el solo fin de proporcionar la corriente que se necesita para la elaboración del cobre en Chuquicamata, y que por esta razón no nos ha sido posible en el pasado acceder a peticiones análogas a la suya, que se nos han hecho tanto de parte oficial como privada (AGT, carta s/n Alfred Houston, Santiago, 21 de marzo 1928).

La negación evidente, quizás técnicamente planteada, poco y nada tenía que ver con la realidad, a saber, que el proceso de iluminación pública sería en términos porcentuales significativamente inferior a la demanda del proceso electrolito de la mina (La Opinión, 23 de marzo 1928). Pero la desarticulación con la comunidad de recepción del proyecto minero es explicitada:

Usted comprenderá que nosotros estamos obligados a tratar ante todo que una planta de la magnitud de Chuquicamata no tenga interrupción alguna (so pena de recibir enormes perjuicios por paralización), interrupciones que podrían ocurrir más fácilmente si la estación de generadores de Tocopilla tuviera que surtir al mismo tiempo a diversas otras entidades. Nos hemos vistos forzados a contrariar vuestros propósitos (AGT, carta s/n Alfred Houston, Santiago, 21 de marzo 1928). 
Meses después, una editorial del diario La Prensa titulada "Luz Eléctrica" (25 de julio 1928) comenzaba criticando el precario escenario local:

Uno de los defectos graves de Tocopilla es el alumbrado público y en los edificios del radio urbano. Podemos vanagloriarnos de que en Tocopilla está ubicada la planta productora de energía eléctrica más poderosa en toda la costa occidental sudamericana y, sin embargo, no hay ciudad peor alumbrada que ésta.

El cronista del diario atribuyó esta problemática a la poca astucia de las autoridades que consintieron a la concesión para construir la termoeléctrica en 1913, "cuya fuerza basta y sobra para mover e iluminar el mineral de Chuquicamata y para alumbrar esplendorosamente el extenso radio rural ocupado por las instalaciones y poblaciones de la compañía propietaria". Según el cronista, dichas autoridades no se cuidaron de conseguir disposiciones compensatorias, lo cual habría sido la de proporcionar luz a las calles y edificios públicos.

Por esto, cuando a los vecinos de Tocopilla empezó a avergonzarlos el uso de las velas y los quinqués, ${ }^{17}$ se intentó construir por dos industriales una pequeña planta cuya potencia fue insuficiente [...] La Municipalidad necesita mejorar el alumbrado público, el comercio y los particulares ponen el grito en el cielo (La Prensa de Tocopilla, 25 de julio 1928).

Frente a la ansiedad y el descontento ciudadano, que generaba incomodidades políticas al municipio, la casa consistorial acude al diario y anuncia: "La municipalidad va a instalar una planta eléctrica" (La Prensa de Tocopilla, 28 de julio 1928). El matutino agregaba:

Las publicaciones que hemos estado haciendo respecto a la necesidad de que se adopten resoluciones decididas de parte de la Municipalidad, en orden a exigir que la empresa proveedora de luz eléctrica atienda a las necesidades del pueblo [...] han movido al Alcalde Francisco Choloux a dar mayor impulso a un proyecto que germina en la Junta de Vecinos para poder dar una solución magnífica del problema (La Prensa de Tocopilla, 28 de julio 1928).

17 El quinqué o lámpara de Argand era un artilugio de mechero circular. Era considerado un artefacto de mejor calidad en la iluminación en comparación con la lámpara de aceite (Com. pers. Sergio Fernández).
La Municipalidad pretendía solucionar el problema asociadamente con la Compañía Salitrera de Tocopilla de Henry Sloman, empresa que ofrecía la venta a bajo precio de tres motores a petróleo para el alumbrado público, "de modo que si llegamos a un acuerdo tendríamos un alumbrado propio desde el mes de enero, con luz permanente en el día y en la noche, y un motor sobrante para emergencia", indicaba Francisco Choloux $^{18}$ a La Prensa de Tocopilla.

El proyecto era auspicioso para la comuna y significaría buenos créditos políticos para un alcalde designado por una tiranía: "La compañía cede el local en donde están funcionando los motores por tiempo ilimitado y gratuitamente daríamos luz al hospital y a la industria urbana". Los motores eran de 394 caballos de fuerza cada uno. No obstante, el presupuesto debía discutirse en 1929. Por su parte, el cronista del diario apuntó: "es gratísimo saber que la Municipalidad ha resuelto en forma decidida ir a la instalación de una planta propia que puede ser la de Sloman" (La Prensa de Tocopilla, 28 de julio 1928). Lamentablemente, este proyecto zozobró por la escasez de recursos y por la muerte de Henry Sloman en 1931.

Los archivos periodísticos atestiguan numerosos titulares, muchos de ellos a modo de pregunta sobre la situación, por ejemplo: "¿Qué se ha resuelto sobre el servicio de alumbrado para Tocopilla? La Gobernación pregunta al Ministerio del Interior". (La Prensa de Tocopilla, 2 de septiembre 1928). Desde entonces, día tras día, la campaña mediática de los diarios locales remitía a los problemas comunales y a la verdadera revolución que se vivía en otros países en donde la electricidad ya era un bien público.

La electricidad ha hecho de todo el mundo el mercado de los comerciantes e industriales. Imaginad que Londres, París o Nueva York carecieran de los actuales servicios eléctricos, estas ciudades quedarían tan distantes una de otra como los polos [...] la electricidad es la sangre de la telegrafía, radiotelegrafía,

18 Francisco Choloux había sido designado en el cargo de alcalde por el presidente Carlos Ibáñez del Campo. Designación que incluyó la disolución de la Municipalidad de Gatico, disolviendo al mismo tiempo la Junta de Vecinos a través del Decreto Supremo 5526 de agosto de 1927. Francisco Choloux era dueño de la principal farmacia llamada "Chile Drug Store" (Galaz-Mandakovic 2012). 
telefonía y cables... (La Prensa de Tocopilla, 24 de octubre 1928, artículo escrito por Hugo Hirst, presidente de General Electric Company).

En estas declaraciones, se incluía el carácter "redentor" de esta "verdadera revolución eléctrica" en el mundo, que impactaba profundamente en la cotidianeidad hogareña:

...iy qué revolución está produciendo la electricidad en la vida doméstica! Para muchas mujeres, aunque felices en sus relaciones domésticas, la vida del hogar les significa demasiado a menudo un trabajo durísimo y penoso -Adicionándole un carácter ahorrista e higienicista-: hoy a cada rama de la vida doméstica, la electricidad ha llevado un verdadero ahorro de trabajo y una gran eficiencia, más horas libres para el placer o para la educación, alimentos más limpios y una higiene mejor.

La apología a la electrificación llegaba a delirantes editoriales en cuanto a que la electricidad era un dispositivo de uniformidad cultural en el orbe:

...hay todavía otro factor: contribuir a la paz mundial, estamos en contacto con una energía que ha sido casi entero causante de todo progreso humano, que valga la pena; en el comercio, en la industria, en la medicina y en la cirugia, en el teatro. La electricidad mediante la radiotelegrafía y la televisión y de toda radiocomunicación en general ha hecho del mundo una sola familia y reunió a todos los pueblos del mundo en una sola ciudad. La distancia será aniquilada (La Prensa de Tocopilla, 24 de octubre 1928).

$\mathrm{Al}$ año siguiente, específicamente en enero de 1929, asume como ingeniero residente en The Chile Exploration Company Félix Layat. A él le fue dirigida una carta por parte del gobernador:

Formalizando una conversación que tuve el agrado de sostener con $U d$. cuando desempeñé las funciones de Alcalde, ruego a Ud. recabar de quien corresponda la aceptación del negocio que en aquella ocasión me permití sugerirle, a saber: que la Chile Exploration Company provea a la Municipalidad de la corriente eléctrica necesaria para el alumbrado de la ciudad.

El gobernador continuó asumiendo su lugar peticionario:

...posiblemente parecerá a Uds. majadero que un Gobernador tras otro, de los venidos acá en los últimos años, repita la proposición. Esta misma insistencia ha sido mantenida por funcionarios distin- tos en épocas también distintas, prueba mejor para demostrar que es ésta la solución que se impone. El señor Houston -antiguo gerente, de quien citamos su carta del 21 de marzo de 1928 un poco más arriba- ha dado a antecesores míos diversas razones encaminadas a demostrar la impracticabilidad de dicho negocio, resultando verdaderamente inconveniente la de que, convertida la Chile Exploration en empresa de energía, recaerían en ella una serie de gabelas impuestas por nuestras leyes. Pero el traspaso por la Chile Exploration a la Municipalidad, de una pequeña porción de corriente, no se haría sino que en el caso de obtener del Supremo Gobierno que esto no signifique para la empresa la más mínima alteración de su situación actual. Creo que, sobre esta base, todo lo demás se reduciría a una cuestión de simple buena voluntad.

En el devenir de la carta, que sin duda expresa una disposición directa, mucho más política y negociante, explicita un párrafo esencial que resume el problema de fondo existente entre la empresa y la realidad local: "Resulta un contrasentido atroz que la ciudad más mal alumbrada de Chile sea precisamente la que alberga en su seno a la más potente planta generadora de Sudamérica!".

La denuncia y la manifestación de la disociación del consorcio con el territorio es sustancial, sintetizando toda la campaña y la cruel paradoja surgida por la frontera técnica construida por la comarca tecnológica.

El espíritu de progreso de la empresa norteamericana no ha de querer que esta situación subsista cuando a ella puede hacérsele fácil, grato y ventajosa de contribuir a evitarlo. Y menos ha de quererlo en los precisos instantes en que el Gobierno del país, dándole muestras de una exquisita deferencia y desprendimiento, va a sacrificar para empezar cuatrocientos mil pesos del peculio nacional para rehacer el camino de Barriles ${ }^{19}$ a Chuquicamata, al cual no está ligado ningún otro fuerte interés que el de la Chile Exploration. El suscrito confía, señor, en que pondrá Ud. su mejor voluntad en darme una respuesta autorizada y precisa, y tan favorable como corresponde a un asunto verdaderamente hacedero a la brevedad posible. Juan Bautista Fuenzalida, Gobernador (AGT, carta n ${ }^{\circ} 57$ dirigida a Félix Layat, Ingeniero Residente de The Chile Exploration Company en Tocopilla, 9 de febrero 1929).

19 Barriles, ubicado a $15 \mathrm{~km}$ de Tocopilla en la fachada oriental de la cordillera de la Costa, es la zona en donde se implementó una estación ferroviaria en 1889 y un aeródromo en la década de 1930. Se llega al aeródromo a través del camino que une Tocopilla con Chuquicamata. 
Estos últimos párrafos son fundamentales, como lo dijimos, la explicitación de la incongruencia o el "contrasentido" dicho por el gobernador, pero también por la indicación de que todo este tema podría ser resuelto basado en la "mejor voluntad" por parte de la compañía. Por otro lado, el funcionario del Estado expone la cuantiosa inversión del Fisco en la habilitación de un camino que articuló Tocopilla con Chuquicamata, camino que solamente usaría la compañía eléctrica, a saber que eran casi los únicos que disponían de camiones y automóviles, siendo esta indicación una forma de establecer cierta reciprocidad interesada en el proceso de lograr que la electricidad se difundiera por Tocopilla.

La década de 1920 culminaría sin mejores noticias para la ciudadanía respecto a los deseos de electrificación. No obstante, la compañía alcanzó importantes ampliaciones y mejoramientos tecnológicos que prosiguieron ensanchando la brecha entre la capacidad de vanguardia de la usina y la oscuridad barrial de Tocopilla.

En marzo de 1930, Juan Bautista Fuenzalida vuelve a expresar la petición ante continuadas denegaciones, esta vez gestionando a través del Intendente de Antofagasta:

\section{Sr. Intendente: con ocasión de su última visita a este Departamento, mostró Ud. interés en obtener que la Chile Exploration suministre a la ciudad de Tocopilla la corriente eléctrica que necesita para su alumbrado. Me es grato manifestarle a este respecto que han hecho gestiones en dicho sentido los Gobernadores Tomás Lawrence, Flo- rencio Tornero, el suscrito, y, últimamente, el Alcalde Murillo, con resultados invariablemente negativos.}

En el resumen del rechazo por parte de la empresa, Fuenzalida sintetizó:

... los dos grandes argumentos que la compañía ha tenido para no acceder consisten en que, convirtiéndose en empresa vendedora de energía, caerían sobre ella diversos gravámenes, en que la planta no da abasto a la necesidad y compromisos actuales. El primero de estos inconvenientes quedaría destruido como se indica en el oficio $n^{\circ} 77$ del 9 de febrero del año pasado-1929-, dirigido por esta Gobernación al representante de la Chile Exploration que fue lo que se hizo en el caso de Chañaral espléndidamente alumbrado hoy por la Empresa de Potrerillos; y en cuanto al segundo, estimo que ha des- aparecido con las poderosas instalaciones de María Elena ${ }^{20}$ para dotar de fuerza eléctrica al ferrocarril.

En esta presentación hay dos datos importantes: el primero sobre la Empresa de Potrerillos y el segundo remitido a la electrificación del ferrocarril salitrero de Tocopilla al Toco (FCTT). Sobre el primero, cabe indicar que Potreri$\operatorname{llos}^{21}$ en la década de 1920 era el resultado de las explotaciones que llevaba a cabo Andes Copper Mining Company. Esta empresa también contempló la construcción de una planta termoeléctrica ubicada en el nuevo puerto de Barquitos, emplazado al costado sur del puerto de Chañaral, este último poblado electrificado por la compañía minera en la década de 1920. De esta forma, se marcó un adelanto tecnológico que dejaba muy atrás a Tocopilla, evidenciando una asimetría en la relación de las compañías norteamericanas con sus respectivas ciudades de emplazamiento.

Por su parte, la electrificación del ferrocarril salitrero de Tocopilla en 1927 despertó serios cuestionamientos a The Chile Exploration por preferir electrificar una compañía y no Tocopilla.22

20 Oficina salitrera fundada en 1927. Desde 1924 la empresa Guggenheim Brothers adquirió salitreras pertenecientes a la Oficina Coya Norte, asumiendo el dominio de la Anglo-Chilean Nitrate \& Railway Co.

21 Potrerillos surgió como campamento minero en manos de norteamericanos, específicamente en 1913, momento en que William Braden compró la Compañía Minera de Potrerillos y todas las pertenencias vecinas, un total de 376 ha. En enero de 1916, Braden vendió todas sus pertenencias a la recientemente creada Andes Copper Company, compañía norteamericana subsidiaria de la Anaconda Copper Mining Company. Entre 1917 y 1927, la Andes Copper realizó trabajos de prospección y construcción en las diferentes áreas de producción. Es en esta década cuando se construyeron las plantas industriales, el ferrocarril entre Pueblo Hundido y Potrerillos, las instalaciones portuarias, el tranque, la planta eléctrica y los campamentos (RMCh 1930).

22 El Ferrocarril Tocopilla al Toco (FCTT) fue inaugurado en 1890 por el presidente José Manuel Balmaceda. En 1927 hubo una renovación sustantiva: se optó por electrificar el convoy y para ello hubo que realizar una alta inversión en cuanto a tendidos eléctricos y renovar completamente las locomotoras. Las nuevas máquinas fueron fundadas en el Condado de Schenectady en el estado de Nueva York, maquinarias especialmente elaboradas para el Ferrocarril de Tocopilla al Toco por la compañía General Electric. El reemplazo de las antiguas maquinarias a vapor Kitson-Meyer fue relevante para cubrir el tramo entre el puerto y El Tigre, ideales y óptimas para superar la gran pendiente deter- 
Por ello el gobernador acusaba la escasa voluntad empresarial:

...insisto, señor Intendente, en que esto es una simple cuestión de buena voluntad para con el país en que la poderosa empresa norteamericana trabaja. No se le pide con esto ninguna dádiva, sino la corriente por su precio de costo. Creo que esto es lo menos que puede solicitarse a una empresa que, no obstante su fuerte arraigo en Tocopilla, nada hace que signifique un apreciable desprendimiento o progreso más allá del recinto en que ella misma se halla instalada. Juan Bautista Fuenzalida (AGT, Oficio no 118 al Intendente de Antofagasta, 18 de marzo 1930).

La campaña del gobernador por la electrificación del pueblo tuvo al Intendente como al mayor receptor de las quejas: "Se eleva al señor Intendente de la Provincia para que, si lo tiene a bien, se digne darle el trámite correspondiente, haciéndosele presente que el llamado alumbrado eléctrico es el peor de los males que afligen a esta ciudad. Juan Bautista Fuenzalida" (AGT, Oficio n 523 al Sr. Intendente, 10 de mayo 1930).

Por su lado, la Municipalidad enviaba el proyecto de una "Planta Eléctrica Municipal" al gobierno de Ibáñez y lo difundía por los diarios La Correspondencia y La Prensa.

Se ha enviado al Gobierno la solicitud de la Municipalidad de Tocopilla para instalar una planta eléctrica con la cual atenderá al alumbrado de calles, paseos y establecimientos públicos, al servicio domiciliario y al abastecimiento diurno de energía para usos industriales. Este proyecto que viene siendo estudiado por técnicos muy competentes, desde principios de este año, se encuentra ya terminado en todos sus detalles y solo falta la autorización de la Dirección de Servicios Eléctricos, para que se proceda a la instalación de la planta y redes distribuidoras después de dada esa autorización (La Prensa de Tocopilla, 20 de mayo 1930).

Finalmente, el cronista de La Prensa de Tocopilla celebraba la moción y proactividad municipal:

La población entera se felicita de que la Municipalidad haya

minada por la cordillera de la Costa. Este ferrocarril estuvo bajo distintas denominaciones del consorcio salitrero: Anglo Chilean Nitrate \& Railway, Chilean Consolidated Nitrate Corporation, Compañía Salitrera Anglo Chilena, Compañía Salitrera Anglo Lautaro, Sociedad Química y Minera de Chile, finalmente SQM (Galaz-Mandakovic 2012). tomado decididamente el único camino que hay que dotar a la ciudad de un buen servicio y no duda de las gestiones que ahora toma a su cargo el Gobernador y Alcalde para que tengan el mejor éxito, ya que no sería admirable que por intereses creados se condenara a Tocopilla a seguir soportando la situación desastrosa en que se la ha mantenido por tantos años (La Prensa de Tocopilla, 20 de mayo 1930).

En su ofensiva, el gobernador y simultáneamente alcalde Juan Fuenzalida vuelve a solicitar a la compañía estadounidense, pero lo hace a través de una carta que es propagada en La Prensa y de este modo, públicamente le ofrece un convenio al gerente norteamericano:

Estoy deseoso de realizar los mayores esfuerzos para mejorar radicalmente la situación, en este sentido, y al efecto acabo de elevar al Presidente de la República la solicitud para que otorgue a favor de la Municipalidad de Tocopilla la concesión para instalar planta termoeléctrica. [...] vengo a rogar a Ud. se digne considerar la posibilidad de otórgarme su ayuda sobre las siguiente bases.

1. La Chile Exploration vendería a la Municipalidad de Tocopilla, a precio de producción, unos 50 a $60 \mathrm{~kW}$, desde las 5 de la tarde hasta las 6 de la mañana, a condición de cortar la corriente sin lugar a reclamo, si no se cancela el valor correspondiente dentro del plazo de ocho días contados desde la presentación de la factura respectiva.

2. La Municipalidad destinaría exclusivamente esta corriente al alumbrado de las calles públicas y dependencias municipales, fiscales y de beneficencia, siéndole prohibido proveer a cualquier título a otras entidades o a particulares, bajo pena de suspender la corriente sin lugar a reclamos.

3. El presente convenio regirá por un año contado desde la fecha de inicio del servicio, pero podría proporcionarse por periodos de común acuerdo entre las partes.

4. La Municipalidad respondería totalmente de los impuestos y gravámenes u otras gabelas que en virtud de este contrato pudiese afectar a la Chile Exploration y se obligaría a obtener del Gobierno la declaración de que ésta no pierde por este contrato su carácter de empresa de servicio privado.

5. La Chile Exploration no tendría responsabilidad alguna en caso de interrupción momentánea o indefinida de este servicio por paralización de sus faenas, por fuerza mayor extra, 
por efecto de huelgas o por cualquier otro motivo análogo ( $L a$ Prensa de Tocopilla, 23 de mayo 1930, carta al gerente general de The Chile Exploration).

Sin duda que el dato que mencionamos más arriba, respecto a los beneficios que había adquirido Chañaral y su electrificación por parte de una análoga empresa minera, era un fuerte ruido para las autoridades y ciudadanos, pero a la vez un buen ejemplo y referencia:

Las bases que envío son análogas a las que sirvieron para el contrato vigente entre Andes Copper Mining Company y la Municipalidad de Chañaral, mediante el cual la ciudad de este nombre goza, tanto como los particulares residentes en ella, de un espléndido servicio de alumbrado... Si la empresa de Potrerillos facilita a Chañaral el alumbrado total con derecho de vender corriente, ipor qué la Chilex no habría de poder convenir con Tocopilla siquiera el alumbrado de sus calles y reparticiones fiscales, municipales y de beneficencia? Juan Bautista Fuenzalida, Gobernador y Alcalde (La Prensa de Tocopilla, 23 de mayo 1930, carta al gerente general de Chile Exploration).

Frente a la presión ejercida por el político, a los pocos días la compañía informó a través de los mismos diarios que el gerente general en Chuquicamata, Mr. Burr Wheeler, había manifestado al gobernador "especial interés" en sus proposiciones. "La compañía ha transmitido por vía aérea a la dirección de la empresa en Nueva York. Tan pronto como tengamos respuestas le daremos conocimiento de ella" (La Correspondencia, 4 de junio 1930).

Pasados 10 días, un titular en La Prensa fortalecía las ilusiones: "La Chile Exploration está dispuesta a proporcionar luz eléctrica a Tocopilla” (14 de junio 1930). Pero esta disposición sería parcelada, no aceptando por completo la propuesta de la Municipalidad, indicando que la entrega de electricidad sería exclusivamente para los usos de alumbrado público y de los servicios del Estado bajo algunas condiciones. Manifiesta además que la transmisión de energía eléctrica sería solamente por tres años.

Toda esta ilusión se desmoronó el 23 de agosto de 1930: "La Chilex no proporcionará alumbrado público a Tocopilla" (La Prensa de Tocopilla). Después de realizar una genealogía de las gestiones que ya hemos comentado, el diario indicaba el detalle del nuevo revés para la ciudadanía:
Los diez puntos planteados por la Chile Exploration entraron en estudio por parte de la Municipalidad y de ello se tuvo que rechazar uno, o sea el principal, el precio del $k W$, que la compañia fijaba en minimum de 40 centavos, condición inaceptable para la Municipalidad, que solo puede pagar 20 centavos por $k W$ hora, con el derecho a expender una parte de la energía para compensar mayor gasto.

El gobernador se vio en la necesidad de rechazar las exigencias de The Chile Exploration por el alto precio y por no convenir a los intereses ciudadanos.

La oscuridad de la ciudad seguía marcando la pauta de los diarios y también la cotidianeidad de los tocopillanos, porque esa misma lobregura implicaba cierta preparación logística para cada vecino que se decidía a caminar: "Cada vecino cuando sale a la calle de noche, va provisto de una linterna eléctrica de mano y bastón, para saber dónde pone los pies porque por desgracia la obscuridad es absoluta" (La Prensa de Tocopilla, 17 de octubre 1930). Adiciónese a lo anterior la casi nula pavimentación y los caminos que usualmente estaban repletos de charcos de aguas servidas.

Frente a todos estos reveses, desde Iquique llegó un ofrecimiento de la Compañía de Alumbrado de Iquique, empresa dirigida por Luis Advis. "La compañía haría aquí sus instalaciones, calculando una inversión de $\$ 1.000 .000$ de pesos...", indicaba el diario La Opinión el 17 de octubre de 1930. Se ofrecía un "moderno servicio, con modernas instalaciones, corriente alterna de cincuenta periodos, 220 volts para alumbrado y 380 volts para fuerza motriz". Además se ofreció una planta de hielo, generando aún más expectativas. Finalmente, el ofrecimiento quedó solo en eso, en palabras y buenas intenciones. La inversión era cuantiosa y nunca se concretó.

"Luz!, luz!!, clama la población de Tocopilla" -titulaba en primera plana La Prensa (23 de mayo 1931, ver figura 3). Luego añadía-: la población, siente sobre sí todo el peso de tal calamidad. Hay cuadras que no tienen ni una miserable ampolleta que derrame luz temblorosa y pobre. La ciudad adquiere un tinte sórdido y miserable en las noches que no cuadra, francamente con lo que se merece en lo tocante a alumbrado.

En noviembre de 1932, La Prensa tituló: "Tocopilla necesita luz y energía eléctrica a precios módicos" (3 de 


\section{LUZ! LUZ!! CLAMA LA POBLACIONDE TOCOPILLA}

No tan pronto, como se suponía, tendremos buena luz en las calles.- Ningun interesado se presentó a las propuestas públicas.- La Municipalidad y su acción tendiente a interesar a alguna firma que tome el contrato

Figura 3. La Prensa de Tocopilla, 23 de mayo 1931. Archivo Gobernación de Tocopilla.

noviembre 1932). Para luego agregar: "el pueblo está en una situación de un villorrio de $3^{\text {a }}$ clase". El matutino reproducía las declaraciones del alcalde Juan Daniel Ruiz que básicamente remitían a la larga data del problema y la nula solución al mismo.

La actitud de las autoridades, especialmente la figura de Juan Daniel Ruiz, era valorada y considerada como "encomiable" al movilizarse para solucionar el problema de la electrificación. "Al pueblo no le pueden importar los intereses de una ni de otra, ni que sean suecos, americanos o yugoslavos quienes nos proporcionen la luz. Lo que quiere el vecindario es que se les suministre luz económicamente y buena" (La Prensa, 5 de noviembre 1932).

La ilusión de un contrato con The Chile Exploration consignaba la supresión de problemas cotidianos, porque "la ciudad debe disfrutar de un alumbrado digno de un pueblo culto y civilizado" (La Prensa, 5 de noviembre 1932).

Según variadas documentaciones municipales y algunas crónicas periodísticas de la década de 1930, el tema de la baja cobertura de electricidad para la ciudad, a saber de su labilidad, también estaba relacionado con la peligrosidad de las instalaciones domésticas. La Opinión informaba:

...en varias ocasiones ha llegado a nuestro conocimiento el hecho de numerosas instalaciones eléctricas en las casas de particulares desde este puerto se encontrarían dispuestas en tal forma que constituyen un peligro para los moradores, por la facilidad con que se originan los cortocircuitos. Esto, naturalmente, sería originado por circunstancias de que tales instalaciones han sido hechas con negligencia o personas inexpertas (La Opinión, 18 de octubre 1935).
Sergio Fernández, antiguo vecino de Tocopilla, nos dice: "Tocopilla no contaba con algún organismo que vigilara directamente las instalaciones en las casas. La gente tenía escasa capacitación para un rubro tan tecnológico como lo representaba la electricidad" (Com. pers., marzo 2015).

El mismo diario La Opinión indicó en 1936:

Se verifican instalaciones que nacen como provisorias, instaladas por los mismos arrendatarios o dueños que sin conocimiento alguno de los peligros de una instalación defectuosa hacen conexiones en descubierto sin tubos de proyección y muchas veces sin huinchas aisladoras (La Opinión, 7 de mayo 1936).

Esta anomalía generaba otro tipo de problemas: los incendios. Amalia Barrera, que nació en Ovalle en el año 1909 y residió en Tocopilla desde 1919, nos comentó que los incendios eran numerosos y el resultado de instalaciones eléctricas defectuosas, improvisadas, mal hechas. La ansiedad por la luminosidad provocaba desprolijidades.

En Tocopilla las casas eran de madera, casi todas, y en los barrios obreros cuando querían poner la luz, la gente ni se fijaba que era peligroso, que podía haber un incendio. Hubo hartos incendios, hasta con niños muertos y también me acuerdo que se quemaron vivos unos viejitos por el barrio El Salto porque habian instalado luz gracias a un motor.... Parece que no supieron cómo hacerla [...] y la casa se quemó porque saltó una chispa... (Com. pers., 14 de febrero 2007).

El diario La Opinión tuvo una especial sensibilidad con este tema, y seguidamente publicaba críticas editoriales frente a la sombría situación: "Estimaríamos muy reco- 
mendablemente que la municipalidad dispusiese de un funcionario idóneo que se encargue de una revisión completa de las instalaciones eléctricas que hay en la ciudad y de las que se hiciesen con el fin de [que] las malas instalaciones sean reparadas" (15 de junio 1936).

Durante décadas la ciudad se iluminaba solamente cuando ocurrían incendios.

\section{Nuevos negociadores}

En 1938 asume la Alcaldía de Tocopilla el destacado dirigente comunista Víctor Contreras Tapia. ${ }^{23}$ Una de sus principales preocupaciones fue subsanar definitivamente el problema de la ausencia de electrificación y superar la lobreguez. En su diario de memorias llamado Campesino y Proletario (1983), señala algunos pasajes de las negociaciones que llevó con el nuevo gerente de The Chile Exploration, Mr. Boynton.

Mi comuna marchaba. Pero había que afrontar la solución de muchos problemas. Uno de los asuntos fue el del servicio eléctrico [...] La población crecía hacia las afueras, tuvimos que ampliar el barrio urbano y había que extender los servicios (Contreras 1983: 104).

El ex alcalde señala que en sus obligados contactos sociales como autoridad, había entablado una relación de respeto con el gerente Arturo Boynton, a quien consideraba una persona distinta, sin las presuntuosas y déspotas actitudes de los otros gerentes, incluyendo a los gerentes de Anglo Lautaro. "Sin embargo, Arturo Boynton era distinto. La gente lo llamaba el 'huaso' Boynton por su trato sencillo" (Contreras 1983: 104).

23 Víctor Contreras Tapia nació en San Esteban el 7 de julio de 1906 y murió en Santiago el 11 de octubre de 2005. Fue un obrero del salitre, dirigente sindical y político chileno. Militante del Partido Comunista desde el año 1927. Tuvo una activa vida pública y dirigencial, por nombrar algunas actividades: presidente del Sindicato de Lancheros de Tocopilla (1936-1939); alcalde de Tocopilla (1938-1945); diputado por Antofagasta, Taltal y Tocopilla (19451949); ministro de Tierras y Colonización (1946-1947); senador por Tarapacá y Antofagasta (1961-1969); ministro plenipotenciario de Chile en la Unión Soviética (1968); senador por Tarapacá y Antofagasta (1969-1973). Tras el golpe de Estado se exilia en la República Democrática Alemana (RDA) (noviembre de 1973). Retornó a Chile en 1983 (Galaz-Mandakovic 2009).
En la narración detalla algunas conversaciones con el "huaso" Boynton:

En las conversaciones que soliamos tener en actos sociales, nunca tocaba los asuntos politicos, pero yo lo llevaba siempre a los problemas que tenía la comuna. Así, le dije que estaba preocupado por la falta de luz en los barrios, donde la gente tenía que alumbrarse como en tiempos de la Colonia, con un chonchón a parafina o con velas. Me respondió que para solucionar eso era necesario instalar una planta eléctrica. -Sí, pero una planta nueva cuesta mucho dinero y la Municipalidad no dispone de ello. La solución-agregué- no es ésa, sino que su empresa proporcione energía eléctrica a la ciudad. Es vergonzoso que, teniendo aquí la planta termoeléctrica más grande del continente, tengamos el alumbrado más malo... (Contreras 1983: 105).

En la continuación de estos pormenores, Contreras Tapia dice:

El gerente me dijo: Nosotros podemos vender energía eléctrica a la Municipalidad... lo malo es que éstas cambian. Yo tengo confianza en la actual administración comunal y no queremos dar problemas. La empresa instaló la planta para dar corriente a su industria y no para hacer negocio, pero podemos estudiar una fórmula. Dígale a su abogado que estudie alguna que permita asociarnos con alguna empresa estatal y yo la patrocino ante la gerencia (Contreras 1983: 105).

El temor del gerente de Chile Exploration consistía en la rotación de líderes que ocurre en la institución municipal, estableciendo, según él, cierto grado de inestabilidad, de desconfianza al tener que tratar cada cierto tiempo con distintos alcaldes, temiendo por ello que, fácilmente, los contratos pudieran ser cambiados y vulnerados según el criterio de cada alcalde.

Pero el tema del alumbrado de la ciudad era la promesa más fuerte de Víctor Contreras Tapia, quien ya llevaba dos años en el cargo sin poder cumplir la tan votada promesa electoral. Pero las óptimas relaciones entre el alcalde y la compañía daban muy buenas luces sobre el éxito de la gestión.

En ese escenario, el municipio de Tocopilla estableció una alianza entre la recientemente creada Corporación de 
Fomento de la Producción (CORFO), ${ }^{24}$ y The Chile Exploration Company. Inicialmente, la Municipalidad no tendría que participar por ser una corporación de carácter político y la Gerencia de The Chile Exploration Company no estaba facultada para realizar contratos con instituciones de estabilidad incierta.

Finalmente, después de 28 años de disociación, desarticulación y cerradura del enclave tecnológico transnacional, la compañía decide abrir sus fronteras, los cables de transmisión dejaron de obviar Tocopilla, y en 1942 se dirigieron a los barrios tocopillanos. A esas alturas, la ciudad ya contaba con más de 15.624 habitantes (XI Censo Nacional de Población de Chile, 1940).

La Prensa (edición del 6 de enero 1949) detallaba el acuerdo, indicando que la Municipalidad aportaría a esta sociedad entre 500 mil y 800 mil pesos, pormenorizando que la parte administrativa y técnica de la futura Compañía de Electricidad de Tocopilla sería resorte de la Corporación de Fomento de la Producción. En cuanto a la parte administrativa, debido a que continuamente cambiaba el personal de las municipalidades, no se podía establecer un control exacto de las operaciones que se realizarían. Esto provocaba la suspicacia de que pudiera prestarse para algunos abusos ya que el administrador no podría tener la suficiente independencia para obrar con energía en caso de ser necesario. En referencia a la parte técnica se inhabilitaron los regidores.

El énfasis estuvo puesto en instituir una clausula que estableció el poder de la Municipalidad en cuanto a imponerse cuando lo estimara necesario respecto a los manejos administrativos, contabilidad y negocios de la compañía por reparticiones municipales o personas que el alcalde designe, dejando en amplia libertad al grupo administrativo de la Corporación de Fomento, la cual podía obrar de acuerdo con los reglamentos que dictaminó la Dirección General de Servicios Eléctricos. Respecto al precio del kW, sería fijado por la Dirección General de Servicios Eléctricos, sin perjuicio de que la Corporación de Fomento o la Municipalidad lo rebajaran si lo estimaban muy alto (La Prensa de Tocopilla, 6 de enero 1940).

24 Creada por el gobierno de Pedro Aguirre Cerda el 29 de abril de 1939 a través de la Ley 6434.

\section{Y se hizo la luz}

Pasaron dos años de gestiones administrativas, de papeleos, de viajes por parte de las autoridades, reuniones técnicas, instalaciones logísticas, hasta que llegó uno de los días más esperados por los tocopillanos, por las autoridades y también por The Chile Exploration Company.

En los diarios locales aparecía la ansiada noticia: "Esta noche se inaugurará el nuevo servicio de alumbrado eléctrico". Era el recordado 14 de marzo de 1942.

En medio de enormes demostraciones de parte del pueblo, se realizó anoche, a las 8, la inauguración oficial del nuevo servicio de alumbrado eléctrico de Tocopilla. Como cosa previa, a las 7 de la tarde, el Administrador del nuevo servicio de alumbrado, señor Florín Moreno, ofreció un cocktail en el Club de la Unión, ${ }^{25}$ al cual asistieron especialmente invitados las autoridades, los jefes de industrias regionales y caracterizados vecinos, detallaba $L a$ Opinión del 15 de marzo de 1942.

En la ocasión se ofreció un discurso por parte del administrador del servicio eléctrico, quien relató cada uno de los pasos dados por el alcalde Contreras, por The Chile Exploration y por los trabajadores de la CORFO. Agradeció personalmente al ingeniero residente, Arturo Boynton y excusó al alcalde Contreras por no encontrarse en la ciudad al momento de la inauguración. ${ }^{26}$

A las 8 de la noche el gobernador Pedro Muñoz Rojas conectó el switch del transformador ubicado en calle Serrano, dando así electricidad al primer sector, ubicado en la zona céntrica de la ciudad, en donde estaba la Gobernación.

Una vez accionado el interruptor, la banda de músicos tocó una diana y el enorme público allí reunido irrumpió en entusiastas aplausos y otras manifestaciones de satis-

\footnotetext{
25 El Club de la Unión de Tocopilla fue fundado el 18 de septiembre de 1897, irónicamente un cortocircuito generó un gran incendio en la madrugada del 9 de mayo del año 2011 significando su completa desaparición.

26 El alcalde Víctor Contreras Tapia se encontraba en la ciudad de Viña del Mar. El conocido como "el dinámico Alcalde", según La Prensa de Tocopilla del 17 de marzo de 1942, estaba en esa ciudad porque le correspondió participar en el Primer Congreso de $\mathrm{Mu}$ nicipalidades de Chile.
} 
facción. Esta parte de la ciudad quedó inmediatamente iluminada en tal forma que parecía como si hubiera salido de las tinieblas (entrevistas a Amelia Barrera, 2007 y Sergio Fernández, 2015).

Enseguida se organizó un desfile de las autoridades precedidas por la banda de músicos y acompañadas de una enorme multitud hacia el lugar en donde se encontraba el segundo switch. Dicho dispositivo fue conectado por el ingeniero residente de la Chile Exploration, el señor Boynton, en calle 21 de Mayo. Luego, la caravana siguió hacia el tercer switch que fue conectado por la señora María de Contreras, esposa del alcalde de la comuna, quien lo activaba en su representación acompañada por el señor Varas Chacana, alcalde subrogante.

Finalmente fue el turno del último switch, situado frente al Estadio Municipal, dando luz a toda la parte alta de la población. Este switch fue conectado por la señora del administrador de la nueva empresa y por una señorita de apellido Erazo, secretaria del mismo servicio. A esas alturas, la columna de gente del pueblo que acompañaba a las autoridades era enorme, ofreciendo cada vez más entusiastas manifestaciones de alegría y satisfacción.

La operación terminó a la 9 de la noche, quedado la ciudad completamente iluminada hasta los caminos diagonales que convergen hacia las rutas que van al interior y hasta los barrios más apartados. "En esta forma, desde anoche, Tocopilla es una de las ciudades mejor iluminadas de Chile" (La Prensa, 16 de marzo 1942).

\section{$*$ Conclusión}

La caracterización de los procesos vividos en Tocopilla adiciona nuevos pasajes a la ciencia social regional y nacional sobre el capitalismo minero en Atacama en la primera mitad del siglo XX.

Consideramos que los procesos locales de esta inserción tecnológica industrial a gran escala y la asimetría que se construye con el poblado, son procesos que se tensionan con la "epopeya virtuosa", tecnofuturista y con gran parte de la narrativa maestra y nacionalista con la que siempre se ha querido caracterizar la historia de Chuquicamata, en cuanto a su envergadura técnica, productiva, social, política y económica.
La metanarrativa historiográfica de Chuquicamata, vista como "la épica clarinada de la victoria" (Gutiérrez y Figueroa 1920: 50), o como la Carnalavaca de Garafulic (1932), la "maravilla de las maravillas" según Petrowitsch (1950), la "tierra roja y heroica" de Núñez (1972), ha invisibilizado al oscuro satélite tocopillano, que además tuvo que dinamizarse siguiendo los requerimientos capitalistas norteamericanos. Una inclusión utilitaria que hasta el día de hoy manifiesta sus costos y sus sacrificios ambientales con la proliferación de metales pesados por efecto de la quema de petróleo y carbón durante más de 100 años.

En ese sentido, "la luz" producida en Tocopilla fue potente para encandilar la influencia del Estado, constituyéndose la ciudad en un escenario multinacional, en una periferia, en una zona exenta del mentado modelo portaliano de Chile. Un exceso de luz norteamericana que encandiló la chilenización en Tocopilla. Americanización, usina, luminosidad y postación que encendió una periferización tocopillana que se tensiona con el proyecto nacional culturalista, militar, administrativo y educativo de la desbolivianización de Atacama.

Esto lo decimos porque las dinámicas económicas y sociales evidenciadas en el pequeño puerto, nos remiten a una desterritorialización nacional, para dar paso a un desarrollo por orden exógeno (Becattini 1992) de la mano de una entidad privada translocalizada. Este proceso constituyó una cartografía económica y tecnológica alóctona produciendo un nuevo paradigma relacional entre capitalistas, población local y Estado.

La inscripción del puerto con la economía global se ejerció constituyendo una asimetría. Porque, como afirma Castells (1996), la economía global capitalista es en sí misma policéntrica, porque va produciendo espacios capitalistas con desarrollos desiguales y jerarquizados. En este sentido, se critica el ya añejo paradigma de los centros y periferias, porque existen nodos que son selectivamente articulados para funcionalizar el orden exógeno.

En esa producción de una geografía, las economías regionales constituyen un mosaico laxamente interconectado de desarrollos geográficos desiguales (Harvey 2014). Es decir, la inserción tecnológica norteamericana fraccionó la ciudad y una parte de ella inauguró flujos interconectados con el orbe capitalista. Como 
indica Harvey: "los desarrollos geográficos desiguales enmascaran convenientemente la auténtica naturaleza del capital" (Harvey 2014: 161).

Del modo como se producen territorios, el capitalismo también produce connotaciones y extensiones semánticas, o derechamente sinonimias. Porque si en el siglo XIX decir lana era sinónimo de Yorkshire, acero era decir Sheffield, metalurgia sinónimo de Birmingham y algodón era igual a Lancashire. Más al sur, decir estaño era igual a Bolivia; decir salitre era decir Chile, decir cobre era equivalente a Chuquicamata y decir termoeléctrica era señalar Tocopilla. Pero esta última era fallida y desintegrada porque durante 28 años estuvo emplazada en una ciudad oscura.

Entonces, podemos afirmar que la inclusión funcional de Tocopilla para el proyecto industrial de Chuquicamata fue óptima, pero tuvo un sustrato de anomalía y asimetría respecto al poblado, el cual tuvo un desarrollo dispar, por tratarse de un puerto que evidencia ausencia de beneficios respecto a las ganancias que generaron las actividades mineras. Esa disparidad repercute en la pauperización de la localidad. Cabe indicar que Tocopilla, desde la década de 1930, fue denominada como la cenicienta de Chile ${ }^{27}$ pero, también fue promocionada a lo largo del siglo XX como la Capital de la Energía. Una zona de sacrificio que vivió la oscuridad y el impacto ambiental para componer otras zonas, las zonas de beneficio.

La inclusión funcional de Tocopilla en el complejo extractivista, estuvo definida por una nueva articulación y la inyección de una acumulación capitalista transnacional. Los nuevos métodos de producción se introdujeron a través de tecnologías complejas importadas.

La expansión de las capacidades cognitivas del capital y de las capacidades tecnológicas, llevó a un proceso continuo de destrucción creativa de los modos tradicionales

27 Un ejemplo de ello fue el titular del diario La Prensa de Tocopilla del 31 de diciembre de 1939, pág. 1. "Tocopilla la 'Cenicienta de Chile' entregó 37 millones de pesos al erario fiscal; sus principales problemas aún están pendientes". Luego indica: "nuestro puerto ha tenido durante los primeros once meses de este año un movimiento ascendiente [...] está demostrado que la importancia de nuestro puerto y cuánto merece que se le oigan sus justas aspiraciones de mejoramiento en todo orden de cosas". e incluyó la constitución de una sucursal tecnológica de economías desarrolladas.

La comarca tecnológica constituida por el capital estadounidense, que poseía una gruesa frontera técnica, superó la noción de territorio nacional, porque transformó Tocopilla en un espacio poroso, caracterizado por la colonización mercantil de un territorio, estableciendo nuevas desigualdades locales. Según la propuesta de Pecqueur (1989), en un territorio con inclusión tecnológica internacional prevalecen las relaciones capitalistas con agentes en tránsito, induciendo segmentación social, representando una innovación relacional que se tensiona con prácticas que pudiesen remitir a una colaboración horizontal o simétrica entre actores anclados a la historia de un territorio. Por su parte Harvey indica que en el caso de una aglomeración industrial, las fronteras nacionales "son siempre borrosas y porosas, pero los flujos entrecruzados en determinado territorio dan lugar a una coherencia lo suficientemente estructurada como para marcar un área geográfica y distinguirla de su entorno" (Harvey 2014: 152).

Evidenciamos, por una parte, el "peticionismo" en la comunidad, que ante las nuevas configuraciones tecnológicas que exhibió la termoeléctrica, necesitó desplazar las más antiguas y tradicionales configuraciones: las velas, las lámparas a parafina, los quinqués, la fogata, etcétera. La termoeléctrica representaba el "vendaval de destrucción creativa” como lo llamó Schumpeter (1942). Vendaval que la comunidad quiso compartir, consumir y re-significar para su propia cotidianeidad. Pero este peticionismo puede ser leído también como una forma de superación de una violencia simbólica. Es decir, en el deseo de no querer participar en una lógica de violencia soterrada o naturalizada. Por el contrario, la comunidad y sus representantes quisieron desnaturalizar la violencia de la oscuridad. Desnaturalizar la paradoja y divergencia del enclave termoeléctrico coetáneo a medios artesanales. La convivencia de dos escalas simultáneas en Tocopilla, de dos tiempos diferentes, de una bipolarización, una eléctrica futurista y otra oscura y tradicional, expresión de la dura disociación y la desconexión del capital extranjero que es miope con sus entornos. 


\section{$*$ Referencias citadas}

ALVEAR, J. 1975. Chile, nuestro cobre. Chuquicamata, El Salvador, Potrerillos, El Teniente, Enami, Mantos Blancos y Andina. Editorial Lastra, Santiago de Chile.

ARCE, I. 1997 [1930]. Narraciones Históricas de Antofagasta. Imprenta Moderna, Antofagasta, segunda edición.

ARDILES, H. 2010. Antofagasta catalizador del desarrollo regional. En: Región de Antofagasta. Pasado, presente y futuro. Universidad Católica del Norte, Antofagasta.

AROCA, P. 2002. Impacto de la Minería en la II Región. En P. Meller (Ed.). Dilemas y debates en torno al cobre. Editorial Dolmen, Santiago.

BECATTINI, G. 1992. Le district marshallien: une notion socioéconomique. G. Benko et A. Lipietz (Eds.). Les régions qui gagnent. Paris.

BERMÚDEZ, O. 1963. Historia del Salitre desde sus Orígenes hasta la Guerra del Pacífico. Ediciones de la Universidad de Chile, Santiago.

BRUECKNER, J. 2011. Lectures in Urban Economics. The MIT Press, Cambridge, Massachusetts.

CADEMÁRTORI, J. 2010. El desarrollo económico y social de la Región de Antofagasta. Primera edición ORDHUM, Departamento de Economía, Facultad de Economía y Administración UCN, Antofagasta, Chile.

CAMPDELACREU, E. 2009 [1949] Tocopilla: una memoria de prueba. Agrupación Cultural y Folclórica Tikopillan.

CASTELLS, M. 1996. La sociedad red. Alianza Editorial, Madrid.

COLLAO, J. 2001. Historia de Tocopilla. Corporación Juan Collao Cerda de Tocopilla.

COMISIÓN CHILENA DEL COBRE. 2009. Estrechez cíclica del mercado laboral en la minería chilena del cobre: Diagnóstico y propuestas. COCHILCO, Santiago.

DAVIS, J. H. 1978. The Guggenheims: An American Epic. Morrow, New York.

FALERO, A. 2015. La expansión de la economía de enclaves en América Latina y la ficción del desarrollo: siguiendo una vieja discusión en nuevos moldes. Revista Mexicana de Ciencias Agrícolas $\mathrm{N}^{\circ} 1: 145-157$.
FIGUEROA, M. 1928. Chuquicamata: la tumba del chileno. Imp. Castellana, Antofagasta.

FOX-PRZEWORSKI, J. 1980. The Decline of the Copper Industry in Chile and the Entrance of North American Capital, 18701916. Arno Press, New York.

FFRENCH-DAVIS, R. y V. TIRONI (Comps.). 1974. El cobre en el desarrollo nacional. Ediciones Nueva Universidad, Santiago de Chile.

GALAZ-MANDAKOVIC, D. 2009. Tocopillanos del ayer II. Retruécanos ediciones, Tocopilla.

GALAZ-MANDAKOVIC, D. 2012. Migración y biopolítica. Dos escenas del siglo XX tocopillano. Retruécanos ediciones, Tocopilla.

GARCÉS, E., M. COOPER, M. BAROS. 2007. Las Ciudades del Cobre. Ediciones Universidad Católica, Santiago de Chile.

GÓMEZ, D. 2010. Conformación de la nortinidad regional. El componente étnico originario. En: Región de Antofagasta. Pasado, presente y futuro. Universidad Católica del Norte, Antofagasta.

GUNDER FRANK, A. 1978. Dependent Accumulation and Under development. The Macmillan Press, London.

GUTIÉRREZ-VIÑUALES, A. 2008. Chuquicamata: patrimonio industrial de la minería del cobre en Chile. Apuntes (Bogotá) 21: 74-91.

GUTIÉRREZ, E. 1926. Chuquicamata, Tierras Rojas. Historia y monografía. Editorial Nascimento, Santiago de Chile.

HARVEY, D. 2014. Diecisiete contradicciones del capital y el fin del neoliberalismo. Editorial IAEN, Quito.

ILLANES, G. 1915. Mineral de Chuquicamata de la Chile Exploration Company (inaugurado el 18 de mayo de 1915). Informe elevado al Supremo Gobierno. Imprenta Universitaria, Santiago de Chile.

LATCHAM, R. 1926. Chuquicamata estado yankee: visión de la montaña roja. Editorial Nascimento, Santiago.

LEVIN, V. 1960. The export economies: their pattern of development in historical perspective. Harvard University Press, Cambridge, Massachusetts. 
MACCHIAVELLO, S. 1923. El problema de la industria del cobre en Chile y sus proyecciones económicas y sociales. Impr. Fiscal de la Penitenciaria, Santiago de Chile.

MARTÍNEZ, G. 1943. Orígenes y desarrollo de Chuquicamata bajo la Chile Exploration Company. Ediciones Revista Universitaria. Santiago, Chile.

O'BRIEN, T. 1989. Rich beyond the Dreams of Avarice: The Guggenheim in Chile. Business History Review 63.

O'CONNOR, H. 1937. The Guggenheims. The Making of an American Dinasty. Covici, Friede Publishers, New York.

PECQUEUR, B. 1989. Le développement local. Syros, Paris.

PETROWITSCH, P. 1950. Cobre, vida y milagros de un metal. Documental. Producción de The Chile Exploration Company, Chuquicamata.

RECABARREN, F. 2002. Episodios de la vida regional. Ediciones Universitarias, Universidad Católica del Norte, Antofagasta.

RMCh: RIQUEZA MINERA DE CHILE. Santiago: [s.n.], 19211933. 12 vols., núm. 96 (oct. 1930), pp. 207-217).

ROSSI, G. 1993. Desarrollo urbano de Tocopilla. Norgener.

SCHUMPETER, J. 1942. Capitalism, Socialism and Democracy. Routledge, Londres.

SOTELO, A. 2004. Desindustrialización y crisis del neoliberalismo. Maquiladoras y telecomunicaciones. Universidad Obrera de México / Escuela Nacional para Trabajadores / Plaza y Valdés, Barcelona.
TAPIA, G. 2001. Chuquicamata, historia con nostalgia. Reportaje de investigación. Ediciones Parina, Antofagasta.

ZAPATA, F. 1975. Los mineros de Chuquicamata, iproductores o proletarios? El Colegio de México, Colección Cuadernos del CES 13, México D. F.

ZAPATA, F. 1977. Enclaves y sistemas de relaciones industriales en América Latina. Revista Mexicana de Sociología 2: 719-731.

ZAPATA, F. 1979. Trade union action and political behavior of the Chilean miners of Chuquicamata. En Peasants and proletarians: The struggle of Third World Workers, R. Cohen, P. Gutkind y P. Brazier (Eds.), pp. 460-481. Monthly Review Press, Nueva York.

\section{Archivos}

AGT: Archivo Gobernación de Tocopilla. AMT: Archivo Municipalidad de Tocopilla

\section{Entrevistas}

BARRERA, Amelia. Ovallina, nacida en 1911, fallecida en 2010. Dueña de casa y residente en Tocopilla desde 1929 hasta 2010. Entrevista realizada el 4 de febrero de 2007 .

FERNÁNDEZ, Sergio. Tocopillano nacido en 1930. Ex trabajador de la compañía salitrera de Tocopilla. Entrevista realizada el 25 de septiembre de 2015 .

\section{Diarios}

Diario La Correspondencia, Archivo Provincial de Tocopilla. Diario El Mercurio de Santiago, Archivo Provincial de Tocopilla. Diario La Opinión de Tocopilla, Archivo Provincial de Tocopilla. Diario La Prensa de Tocopilla, Archivo Provincial de Tocopilla. 